\title{
Work in Progress: How Traumatic Events Help Shape Social Exclusion in Engineering Teams
}

\section{Ms. Tara C. Langus, University of Nevada, Reno}

Tara C. Langus is a Ph.D. student pursuing her degree in STEM Education at the University of Nevada, Reno (UNR). Prior to graduate school, she completed Bachelor's and Master's degrees in Biology in which she studied insect immunology and chemical ecology. She has six years of teaching experience and serves as the instructor for the Women in Science \& Engineering Program (WiSE), an academic based resource and professional development program for first-year undergraduates pursuing STEM majors. Her research interests include student attitudes toward diversity, integrating socioscientific and sociopolitical issues in the college STEM classroom, and increasing the representation and retention of underrepresented minorities in STEM.

\section{Mr. Nelson S. Pearson, University of Nevada, Reno}

Nelson Pearson is a Ph.D. student at the University of Nevada, Reno. His research interest includes social networks and the integration of diverse populations, engineering culture, supporting a sense of belongingness, as well as engineering pedagogy. His education includes a B.S. and M.S. in Civil Engineering from the University of Nevada, Reno.

\section{Mr. Justin Charles Major, Purdue University, West Lafayette}

Justin C. Major is a third-year Engineering Education Ph.D student and National Science Foundation Graduate Research Fellow at Purdue University. Prior to graduate school, he completed Bachelor's degrees in both Mechanical Engineering and Secondary Mathematics Education at the University of Nevada, Reno with a focus on K-12 Engineering Education. Justin's current research focuses on the storied experiences of socioeconomically disadvantaged students at intersections of race/ethnicity, class, and gender in engineering education.

\section{Dr. Allison Godwin, Purdue University, West Lafayette}

Allison Godwin, Ph.D. is an Assistant Professor of Engineering Education at Purdue University. Her research focuses what factors influence diverse students to choose engineering and stay in engineering through their careers and how different experiences within the practice and culture of engineering foster or hinder belongingness and identity development. Dr. Godwin graduated from Clemson University with a B.S. in Chemical Engineering and Ph.D. in Engineering and Science Education. Her research earned her a National Science Foundation CAREER Award focused on characterizing latent diversity, which includes diverse attitudes, mindsets, and approaches to learning, to understand engineering students' identity development. She has won several awards for her research including the 2016 American Society of Engineering Education Educational Research and Methods Division Best Paper Award and the 2018 Benjamin J. Dasher Best Paper Award for the IEEE Frontiers in Education Conference. She has also been recognized for the synergy of research and teaching as an invited participant of the 2016 National Academy of Engineering Frontiers of Engineering Education Symposium and the Purdue University 2018 recipient of School of Engineering Education Award for Excellence in Undergraduate Teaching and the 2018 College of Engineering Exceptional Early Career Teaching Award.

\section{Dr. Adam Kirn, University of Nevada, Reno}

Adam Kirn is an Assistant Professor of Engineering Education at University of Nevada, Reno. His research focuses on the interactions between engineering cultures, student motivation, and their learning experiences. His projects involve the study of student perceptions, beliefs and attitudes towards becoming engineers, their problem solving processes, and cultural fit. His education includes a B.S. in Biomedical Engineering from Rose-Hulman Institute of Technology, a M.S. in Bioengineering and Ph.D. in Engineering and Science Education from Clemson University. 


\title{
WIP: How Traumatic Events Help Shape Social Exclusion in Engineering Teams
}

\begin{abstract}
This Work In Progress (WIP) research paper explores the impact of traumatic events on student learning alongside the emergence of team roles and belongingness in first-year engineering course. Previous work studying engineering culture has noted a divide between social and technical content, the emergence of a chilly climate, and that this culture influences engineering teams. While previous research has examined engineering culture, limited work has explored how these elements intersect and are enacted. For our study, we seek to understand how students working on a first-year engineering design team negotiate their team roles and experiences. Specifically, we examine the complex interactions between an all female team and the tensions that arose amidst conflicts with inclusion, power dynamics, and an unannounced traumatic life event. We show how these tensions might contribute to a chilly climate in engineering education not just from the dominant masculine culture but also from peer interaction.
\end{abstract}

\section{Introduction}

Descriptions of engineering culture have often noted the divide between social and technical content as a force in cultivating a chilly and uninviting climate [1]. The emergence and perpetuation of engineering's uninviting culture can have a negative influence on the actions of individual members of engineering teams, and be a strong indicator of overall team performance [2]. Research has shown that the areas in which cultural pressures of engineering can influence teaming include but are not limited to the development of team roles, project task distribution, and the clarity of which goals and objectives are defined and met across a team [3-5].

While previous research has examined the different aspects of engineering culture and the socialtechnical divide on teaming performance, limited work has explored how inevitable life events that trigger trauma in students, adversely impact academic and social integration in engineering teams. Specifically, this work in progress (WIP) aims to explore how dealing with death in college can impact student learning alongside the emergence of team roles and belongingness in a firstyear engineering course.

\section{Background}

Research has found that $22 \%$ to $30 \%$ of college undergraduates have or will experience a traumatic loss (i.e., death of a loved one) within a current year, while $35 \%$ to $48 \%$ are within the first 2 years of the grieving (or bereavement) process [6], [7], [8]. Although the psychological and emotional response caused by experiencing a traumatic personal loss can vary in intensity, the stages of grief with which one mourns loss can be multidimensional, and the duration of bereavement cannot be anticipated [9]. Experiencing a traumatic event can affect people in different ways and coping with grief as a college student can act as a catalyst for decreased academic performance and social exclusion [7],[10].

Further, the expression of grief caused by the trauma of losing a loved one has been met with a gendered response in society at large. Specifically, when grieving the death of a parent, studies show female college students receive limited social support [6], [11] and feel disconnected from their peers, with Silverman [12, p. 393] reporting that these students are often told, "you'll get over 
it". These types of responses further alienate women and perpetuate norms of overlooking how emotional labor is done [13] in gendered spaces. While trauma has been studied at large and for different groups within society, it has received little attention in the unique cultures of engineering and how it influences engineering teaming experiences.

\section{Methodology}

The work in this paper emerged as part of a larger study aimed at understanding first-year engineering students' attitudes, beliefs, and perceptions of diversity before and after working in diverse engineering design teams (NSF EEC-1531586, -1531174). Here, we report on preliminary findings from a set of two approximately 60-minute semi-structured interviews with members of one of our teams. Interviews were conducted the semester immediately following the team's introductory engineering design course, to better focus on their salient teaming experiences. Directed content analysis was used to analyze and understand students' interview responses [14]. This approach allowed us to utilize a priori codes developed as part of the larger project while allowing for new themes to be defined throughout the analysis process. To improve our understanding and address concerns of legitimation, the research team met frequently for in-depth discussion and consensus of consistent occurring themes [15].

This paper presents the perspective of a female dominant engineering team, a team we have called Team Brave, and how they negotiated and reconstructed team roles alongside unspoken trauma. The three female students described in this study, Claire, Clinton, and Lacy (one Latina, one white, and one multi-ethnic) were enrolled in a semester-long, team based, introductory engineering design course at a land-grant institution. Their declared majors were environmental, electrical and biomedical engineering, respectively. Pseudonyms are used for all students, as well as only including limited demographics to maintain participant confidentiality. All data collection and reporting practices were approved by the local Institutional Review Board (IRB).

\section{Findings}

Throughout analysis, three themes related to team roles were apparent as each student described the evolution of these team roles and how they translated into their individual experiences working on a female dominant, first-year engineering team: (1) the manifestation of team roles, (2) group dynamics and forced skill shifts, and (3) perceptions of team performance. Given the preliminary nature of this WIP, we provide initial findings around the manifestation of team roles and perceptions of team performance in light of Lacy's experienced trauma during the semester.

\section{The Manifestation of Roles In an Engineering Design Team}

Initially, Team Brave sought a fair distribution of project tasks at the beginning of the semester. However, specific team roles were not clearly defined or purposefully assigned and instead manifested arbitrarily based on students' perceptions of project task priorities. Clinton, who was proficient with Excel, deemed she was naturally positioned to fulfill treasury tasks. Claire, whose hesitancy of becoming too specialized in a duty or task she could potentially botch, took on a neutral role helping wherever she was needed. Finally, Lacy haphazardly took on an assumed leadership role. She explains more:

I think I was technically team leader. We gave everybody roles at the beginning of the semester. I don't know that they necessarily were what we played, but they were 
just kind of the names we gave each other. [The roles] weren't something that could really be applied all the time (Lacy).

\section{Team Performance Alongside Trauma}

Not evident to the rest of Team Brave was that, midway through the semester, Lacy had experienced the death of a parent. As the semester continued to progress, participation and engagement within Team Brave began to wane, causing a shift in team leadership. Clinton, characterized as the most outspoken and strongly opinionated, felt jaded by what was perceived as Lacy's lack of quality work due to dissociating herself with the group and being less involved with the design project as a whole.

I just had slightly more stuff to do that I felt the team leader should have done. It just seemed like she was checking out a lot. A good chunk of the time she was on her phone (Clinton).

Lacy had completely disengaged from her team, burying herself into her cell phone during class time, and skipping team meetings altogether. While Lacy's unspoken tragedy unintentionally forced tension into the group dynamic, her teammates defaulted to connecting her disconnected behavior to her gender expression and perceived lack of technical abilities as an engineer:

Sometimes [Clinton] was a little condescending in conversations apart from meetings because Lacy liked to do makeup, hair, and stuff like that. So Clinton would be like, "I don't know how she's going to be an engineer. She's not oriented like that" (Claire).

Further, when evaluating each team member's contribution, as is common practice in engineering [16], team members questioned Lacy's reliability and commitment to the design project. Though Lacy contributed to written assignments and worked on the design project at home during her own time, for some on the team this was viewed as a feeble attempt to earn an equal grade. However, Lacy perceived that she had made an effort to share design ideas with her group but brushed off any indication that her ideas weren't always accepted. Lacy's lack of input and overall sense of exclusion during the engineering design process was echoed by Claire:

I feel like she just didn't have any input in the [project] or didn't feel confident in adding anything because of how sometimes she was put down (Claire).

We discovered through the course of Lacy's interviews, that she was not comfortable disclosing her parent's illness, and eventual death, in engineering. Lacy's choice to internalize her loss rather than share this traumatic event, may have led to her disconnecting from her team. Furthermore, this may have influenced the team's perception of her as withdrawn and unreliable. Eventually, this led to her team questioning her technical abilities as an engineer due to her gender expression and perceived lack of ability, despite her coming from a family of engineers.

\section{Discussion: What We Can Learn from Lacy's Story}

Lacy's decision to not share her traumatic experiences with her engineering team indicated a concern that these experiences might not have felt welcome in engineering environments. This 
finding further supports conversations of a social technical divide in engineering environment [17], [18]. The traumatic effects of Lacy's experience led to a decline in academic performance, mirroring previous findings [7], [10], but also led to her team making gendered assumptions about her abilities and performance. This result aligns with previous findings showing that students are less willing to act to support diverse students over the course of a semester in engineering [19]. Further a lack of skills or courage in supporting a peer experiencing grief [6] may have exacerbated the undermining actions of Team Brave.

The interpretations made in this work are based on the limited information that Lacy and her team were willing to share at the time of the interviews. While the data that allow insight into Lacy's experience are limited, her experience raises several questions for engineering educators. Do we allow space for bereaved college students to cope with grief and manage their immediate personal needs that reside outside of their engineering obligations? As instructors, do we take appropriate steps to help find support resources for navigating university bereavement policies? Are we making the appropriate efforts in teaching social-emotional competence for engineers? How do the ways in which students construct team roles in engineering teams allow for the establishment of pathways for difficult conversations around personal trauma?

These results indicate that traumatic issues manifest within engineering teaming performance, but are not valued or prioritized topics of discussion by the bereaved or those who could provide support. This work extends the body of literature on team formation by highlighting a need to create inclusive teaming environments in which individuals can bring their entire selves to the team and the work.

\section{Future Work}

As part of this continuing research, we hope to refine our understanding of how trauma, grief, and bereavement can influence engineering team dynamics. To advance our understanding we will combine the analysis of Team Brave with teams interviewed at other institutions to develop a robust understanding of how students understand and utilize diversity within an engineering environment and how the experiences of Team Brave may be unique. Additional work should explore how traumatic events are perceived and handled within engineering environments by all members of the engineering education community. Specifically, the messaging around emotional expression should be examined to determine what explicit and implicit barriers are constructed in engineering. Through advanced understanding in this area we can begin to create models that support students through challenges that manifest in and out of the engineering classroom.

\section{Acknowledgments}

This work was funded by grants from the National Science Foundation (EEC-1531586/1531174, DGE-1333468). Any opinions, findings, and conclusions or recommendations expressed in this material are those of the authors and do not necessarily reflect the views of the National Science Foundation. The authors would also like to thank members of the STRIDE and PRiDE research teams who helped with data collection and analysis. 


\section{References}

[1] E. Seymour and N. Hewitt, Talking About Leaving: Why Undergraduates Leave The Sciences, Westview Press, Boulder, CO, 1997.

[2] K.L. Tonso, "Engineering Gender-Gendering Engineering: A Cultural Model For Belonging," Journal of Women and Minorities in Science and Engineering, vol. 5, no. 4, pp. 365-405, 1999.

[3] D. Levi and C. Slem, "Teamwork in Research and Development Organizations: The Characteristics of Successful Teams," International Journal of Industrial Ergonomics, vol. 16, pp. 29-42, 1995.

[4] K.L. Tonso, "Teams That Work: Campus Culture, Engineering Identity, and Social Interactions," Journal of Engineering Education, vol. 95, pp. 25-37, 2006.

[5] L.J. Hirshfield, "Equal But Not Equitable: Self-Reported Data Obscures Gendered Differences in Project Teams," IEEE Transactions on Education, vol. 61, no. 4, 2018

[6] D.E. Balk, "Death Bereavement and College Students: A Descriptive Analysis," Mortality, vol. 2, no. 3, pp. 207-220, 1997.

[7] D.E. Balk, "College Student Bereavement, Scholarship, and The University: A Call For University Engagement," Death Studies, vol. 25, no. 1, pp. 67-84, 2001.

[8] D.E. Balk, "Grieving: 22 to 30 Percent of All College Students," New Directions For Student Services, vol. 121, pp. 5-14, 2008.

[9] E. Kubler-Ross, On Death and Dying, Macmillan, New York, 1969.

[10] H.L. Servaty-Seib and L.A. Hamilton, "Educational Performance and Persistence of Bereaved College Students," Journal of College Student Development, vol. 47, no. 2, pp. 225-234, 2006.

[11] B.E. Cox, J.G. Dean, and R. Kowalski, "Hidden Trauma, Quiet Drama: The Prominence and Consequence of Complicated Grief Among College Students," Journal of College Student Development, vol. 56, no. 3, pp. 280-285, 2015.

[12] P.R. Silverman, "The impact of parental death on college-age women," Psychiatric Clinics of North America, vol. 10, pp. 387-404, 1987.

[13] R. Connell, R. Gender: Short Introductions, 2nd ed., Polity Press, Malden, MA, 2009.

[14] H.F. Hsieh and S.E. Shannon, "Three approaches to qualitative content analysis," Qualitative Health Research, vol. 15, no. 9, pp. 1277-1288, 2005.

[15] D.G. Willms, A.J. Best, D.W. Taylor, J.R. Gilbert, D.M.C. Wilson, E.A. Lindsay, and J. Singer, "A systematic approach for using qualitative methods in primary prevention research," Medical Anthropology Quarterly, vol. 4, no. 4, pp. 391-409, 1990.

[16] M.L. Loughry, M.W. Ohland, and D.J. Woehr, "Assessing Teamwork Skills for Assurance of Learning Using CATME Team Tools," Journal of Marketing Education, vol. 36, no. 1, pp. 5-19, 2014.

[17] E. Godfrey and L. Parker, "Mapping the Cultural Landscape in Engineering Education," Journal of Engineering Education, vol. 99, pp. 5-22, 2010.

[18] W. Faulkner, "Dualisms, hierarchies and gender in engineering." Social Studies of Science, vol. 30, no. 5, pp. 759-792, 2000.

[19] A. Godwin, A. Kirn, and J. Rohde, "Awareness without action: Student attitudes after engineering teaming experiences," International Journal of Engineering Education, vol. 36, no. 6A, pp. 1878-1891, 2017. 